\title{
Produção Científica em Turismo: análise de estudos referenciais no exterior e no Brasil
}

\author{
Tourism Scientific Production: referential papers analysis in Brazil and abroad
}

Mirian Rejowski ${ }^{1}$

\begin{abstract}
Resumo
Pesquisa documental, de caráter exploratório, que descreve e analisa os enfoques e resultados de um conjunto de estudos sobre a produção científica em Turismo no exterior e no Brasil, com base em levantamento bibliográfico e análise de conteúdo. Com o objetivo de discutir a relevância e o estágio evolutivo do conhecimento turístico, apresenta uma amostra de estudos referenciais sobre o tema no exterior e mapeia 24 estudos produzidos nessa temática no Brasil de 1993 a 2008, destacando diferentes objetivos, objetos de estudo, metodologias e resultados. A maioria das pesquisas no exterior apresenta-se como quantitativa, centra-se em periódicos científicos e destaca-se pelo referencial teórico e a metodologia adotada. No Brasil, embora a maioria das pesquisas privilegie as dissertações e teses acadêmicas enquanto objeto de estudo há maior diversidade deste; nota-se, porém, certo distanciamento em relação ao referencial teórico e metodológico dos estudos do exterior.
\end{abstract}

Palavras-chave: turismo; produção científica; pesquisas referenciais; estágio evolutivo.

\section{Abstract}

This is an exploratory documental research, it describes and analysis the approaches and results of a group of scientific papers about both foreign and Brazilian tourism, with fundamental principle in bibliographic survey and content analysis. The goal is to debate the relevance and the touristic knowing evolutive stage, with a sample of referential papers about the same issue abroad and it maps 24 papers produced about this issue in Brazil from 1993 to 2008, distinguishing different goals, studying subjects, methodologies and results. Most of the foreigner investigations features itself as measurement, focusing on scientific journals and salients the theoretical referential and adopted methodology. In Brazil, although most of investigations privileges essais and academical thesis as a research matter, we found more diversity of the last, it is possible to notice a place at a distance from the theoretical and methodological reference from abroad.

Keywords: tourism; scientific production; referential investigations; evolutive stage.

\footnotetext{
${ }^{1}$ Bacharel em Turismo, Mestre e Doutora em Ciências da Comunicação e Livre Docente em Teoria do Turismo e do Lazer pela Universidade de São Paulo. Professora associada (aposentada) da Escola de Comunicações e Artes da USP. Docente Titular do Mestrado em Hospitalidade da Universidade Anhembi Morumbi. Pesquisadora bolsista (PQ) do Conselho Nacional de Desenvolvimento Científico e Tecnológico. Email: mirwski@gmail.com.
} 


\section{Introdução}

Em pesquisa desenvolvida no triênio 2007 a 2009 sobre a Pesquisa Científica em Turismo no Brasil, a fim de estudar a comunicação, produtividade e posicionamento, foram desenvolvidos três capítulos teóricos fundamentais ao seu desenvolvimento: turismo como campo de estudo e pesquisa, fatores de evolução da pesquisa científica em Turismo no Brasil, e produção e comunicação científica em Turismo (REJOWSKI, 2010). Este artigo apresenta parte desse último capítulo, centrado no tema Produção Científica em Turismo, com os objetivos de: a) descrever uma amostra de estudos publicados no exterior, ao lado de mapear os estudos de pesquisadores brasileiros publicados em sua maioria no Brasil até 2008; b) sistematizar os enfoques e resultados dessas pesquisas, analisando e discutindo sua relevância e seu estágio evolutivo.

Quanto mais rápido e diversificado o desenvolvimento de uma área, maior a necessidade de pesquisas sobre a sua produção científica, ou de avaliação desta. Daí a importância da:

[...] realização de pesquisas de metaciência, que permitem analisar e avaliar a qualidade e efetividade do conhecimento produzido em uma determinada área, bem como suas necessidades e déficits. O próprio progresso científico se relaciona ou depende de avaliações sistemáticas da produção e do trabalho dos pesquisadores, o que garante o aperfeiçoamento constante não só do conhecimento, como também do próprio ensino. (GALEMBERCK, 1990, p. 627-628)

De um lado, estudos que avaliem a produção científica decorrente das pesquisas turísticas, demonstrando as suas particularidades no contexto do campo recente de estudos que é o Turismo, podem oferecer importantes subsídios para a definição de critérios e indicadores de avaliação da produção científica na área. De outro, tratar da comunicação científica em Turismo, em especial da comunicação formal escrita (impressa ou eletrônica), envolve a compreensão do seu processo ou fluxo e suas particularidades, que podem então ser comparadas com áreas mais consolidadas. Nesse sentido, tais estudos podem refletir o "estado-da-arte" de uma área ou campo de estudos, como o estágio atual do conhecimento científico em Turismo no Brasil.

Acredita-se que esta pesquisa documental, de caráter exploratório, além de preencher uma lacuna bibliográfica no estágio atual da pesquisa em Turismo, contribuirá para a compreensão 
do discurso científico de acadêmicos da área, cuja produção vem aumentando quali e quantitativamente.

O levantamento de bibliografia sobre o tema foi realizado face à consulta a: bases de dados de teses e publicações científicas; índices dos principais periódicos científicos publicados no exterior e no Brasil; indicação de textos por experts da área; e anais de eventos científicos, direta ou indiretamente relacionados ao Turismo, em especial a partir de 2005. A leitura atenta de cada documento levou ao seu fichamento orientado aos fins da pesquisa, e os dados assim coletados foram então organizados e sistematizados em dois tópicos. O primeiro apresenta uma amostra de estudos referenciais sobre a produção científica em Turismo no exterior, e o segundo mostra um mapeamento, ainda que parcial, dos principais estudos que tratam do tema no Brasil.

\section{Pesquisas sobre a Produção Científica em Turismo no Exterior: amostra de estudos referenciais}

Uma primeira análise da literatura internacional sobre a produção científica em Turismo mostra um conjunto significativo de pesquisas, cujos objetos de estudo enfocam destacadamente as teses acadêmicas e os periódicos científicos.

O primeiro trabalho a ser mencionado nesta pesquisa é o de Jafari e Aaser (1988) que abordam o Turismo como tema de teses de doutorado produzidas nos Estados Unidos entre 1951 e 1987, como um importante indicador da evolução do conhecimento científico. Observam o crescimento esporádico e contínuo dessa produção nas décadas de 1980 e 1990 e a sua grande incidência de pesquisas acadêmicas nas áreas de Economia, Antropologia, Geografia e Recreação. Consideram o Turismo como um campo recente de estudos, com uma pequena comunidade de pesquisadores principalmente oriundos das Ciências Sociais. Essa pesquisa obteve grande repercussão em vários países, originando trabalhos como os de Hall (1991) na Austrália e Rejowski (1993) no Brasil.

Já na década de 2000, tem-se o trabalho de Boterill (2002) que traz um levantamento e análise de 149 teses de doutorado aceitas no Reino Unido (e Irlanda) entre 1990 a 1999. Os documentos foram selecionados em um abrangente índice de teses em múltiplas buscas 
utilizando as seguintes palavras-chave: "holiday" (feriado), "holidaymaker" (pessoas em férias), "holidays" (feriados), "tourism" (turismo), "tourist" (turista), "tourists" (turistas), “travel” (viagem), "visitor" (visitante) e "visitors" (visitantes).

Os resultados deste estudo são descritos por ano de aprovação, categorias de assunto, local ou campo de estudo e métodos de coleta e análise. Em síntese, as universidades de Strethcycle (Escócia) e Surrey (Inglaterra) produziram aproximadamente 25\% de todas as teses no período; e a quantidade das teses cresceu de 4 em 1990 para 29 em 1997, com uma significativa média anual de 23 desde 1996. Dentre as 22 categorias temáticas criadas pelos autores, destacaram-se 4 delas mencionadas em cerca de 50\% das pesquisas: desenvolvimento, impacto, comportamento e "indústrias". Houve uma expansão dos locais das pesquisas em regiões do mundo, mas prevaleceu o Reino Unido com aproximadamente $25 \%$ das pesquisas produzidas. A análise dos métodos confirma a influência dominante da epistemologia positivista (questionário) e da hermenêutica (entrevista) nas teses investigadas. (BOTERILL, 2002)

Contatos com pesquisadores de Portugal e da Espanha no início de $2010^{2}$ indicam que estão sendo desenvolvidas pesquisas sobre a produção acadêmica em Turismo nesses países com base em dissertações e teses de doutorado, a fim de compreender a evolução e caracterização do conhecimento científico na área. Esse interesse tardio pode ser explicado, no caso de Portugal, face aos estudos de pós-graduação "stricto sensu" em Turismo terem se iniciado apenas em meados da década de 1990 com o primeiro doutorado na Universidade de Aveiro (1995), seguido pela abertura de mestrados somente a partir de $2000^{3}$. Já na Espanha, a primeira tese de doutorado foi defendida em 1979 por Manuel Figuerola Palomo sobre economia do turismo, mas os estudos turísticos somente passaram a fazer parte do sistema universitário espanhol em 1996.

Quanto aos estudos que tratam de periódicos científicos, publicados no exterior, em um deles, Pechlaner et al. (2004) citam que os estudos sobre rankings de periódicos consideram tanto dados objetivos (contagem de citação) quanto a qualidade de percepção de experts da área.

\footnotetext{
${ }^{2}$ Durante a Conferência Internacional INVTUR 2010 - Investigação em Turismo: O Estado da Arte e Perspectivas de Futuro, realizada de 10 a 13 de março de 2010 em Aveiro (Portugal).

${ }^{3}$ De acordo com informações do pesquisador Jorge Humberto Assis Pacheco dos Santos, durante Conferência Internacional INVTUR em maço de 2010 na Universidade de Aveiro.
} 
Nesse sentido, apresentam um "ranking" de 22 revistas científicas de Turismo, a partir de um questionário enviado a 1.054 membros da Travel and Tourism Research Association (TTRA) e da Association Internationale d' Experts Scientifiques du Tourisme (AIEST).

As revistas foram "ranqueadas" de acordo com a freqüência de leitura, relevância científica e prática, reputação e impacto na carreira acadêmica dos pesquisadores. Os autores utilizaram sete pontos de escala do tipo Likert para medir a opinião dos experts turísticos quanto aos atributos de qualidade das revistas pesquisadas. As revistas "top" do "ranking" são três: Annals of Tourism Research, Journal of Travel Research e Tourism Management. Entretanto esse "ranking” é sensível ao país de origem dos periódicos: nos Estados Unidos, o Journal of Travel Research aparece em primeiro lugar, e em outros países o Annals of Tourism Research é o "número um", o que atesta a existência de diferenças de percepção da importância desses periódicos de acordo com o país de origem dos mesmos.

Outro estudo nessa linha é o desenvolvido por McKercher, Law e Lam (2006) sobre a avaliação dos periódicos científicos em Turismo e Hospitalidade ${ }^{4}$ pelos membros ("pares") da comunidade acadêmica. Os autores consideram que o "ranking" e a avaliação de periódicos científicos é uma questão controversa em campos estabelecidos e emergentes de estudo. Analisam mais de 40 estudos sobre o tema, e mencionam que, apesar dos esforços, não há métodos infalíveis, ou seja, cada método tem méritos e deficiências, sendo os mais comuns os seguintes: índices de citação e fator de impacto, taxas de aceitação, "downloads" de "sites" eletrônicos ou bibliotecas, uso de painéis de "experts" e revisão por pares.

Adotando esse último método na pesquisa, os autores analisam um conjunto de periódicos editados em inglês, sendo 40 de Turismo, 30 de Hospitalidade e Serviços de Alimentação, e 16 de Lazer e Recreação. Aplicaram um questionário a 314 "experts" de Turismo e 191 de Hospitalidade, os quais foram argüidos sobre os critérios usados para distinguir periódicos de pesquisa de alta qualidade. Como a taxa de retorno dos "experts" em Lazer e Recreação foi baixa, os periódicos dessa área não foram incluídos na pesquisa.

Os periódicos que marcaram mais de 60 pontos em cada uma das áreas estudadas foram os seguintes: em Turismo, Annals of Tourism Research, Tourism Managment e Journal of Travel Research, confirmando o resultado de Pechlaner et al. (2004); em Hospitalidade e Serviços de

\footnotetext{
${ }^{4}$ Aqui hospitalidade deve ser compreendida como hospitalidade comercial, com destaque para a hotelaria.
} 
Alimentação, Cornell Hotel and Restaurant Administration Quaterly, International Journal of Hospitality Management e Journal of Hospitality \& Tourism Research. Verificam também que "as avaliações são dinâmicas, com os acadêmicos mais jovens 'júniors' expressando opiniões diferentes do que os mais idosos" (MCKERCHER; LAW; LAM, 2006, p. 5). Concluem que a comunidade científica, coletivamente, avalia essas publicações em uma clara hierarquia baseada na combinação de consciência e percepção da qualidade dessa literatura.

Apesar dos estudos sobre a avaliação de periódicos científicos serem relevantes, concorda-se com Jamal, Smith e Watson (2006, p. 67) ao criticarem a situação dos estudos sobre o tema, pontuando alguns equívocos e confusões recorrentes, face ao que propõem inovações na classificação, avaliação e disseminação do conhecimento na área. Destacam que há imprecisões e contradições em vários métodos de avaliação desses periódicos, como nos fatores de impacto e na análise de citações, além da subjetividade e deficiências inerentes a diversas bases de dados de artigos científicos. Defendem a revisão dos cálculos desses indicadores, a fim de refletir melhor a diversidade e a legitimação da evolução dos estudos turísticos.

Tendo em vista que o reconhecimento do Annals of Tourism Research pela comunidade científica internacional, importa citar a pesquisa desenvolvida por Xiao e Smith (2006) sobre o seu conteúdo com base no índice temático de artigos publicados de 1973 a $2003^{5}$. Esse período foi então subdividido em subperíodos de seis anos, para a análise dos cabeçalhos de assuntos primários, áreas temáticas e a sua variação no decorrer do tempo, além das contribuições dessa revista para a evolução do conhecimento científico em Turismo.

Esses estudiosos identificam 27 temas principais, sendo que 13 deles foram os mais citados e comuns a todos os subperíodos: metodologia, desenvolvimento, impactos, organização e associação, Estados Unidos, turista, turismo intermitente, planejamento, complexos turísticos, cultura, marketing, motivação e atrativos. Dentre os temas, agrupados em metacategorias temáticas, destacam-se metodologia e conceituação teórica e desenvolvimento e impactos, representando os grandes domínios de conhecimento da pesquisa turística. Analisam ainda alguns padrões temporais amplos, indicando que o campo está evoluindo em termos de temática de pesquisa e de sofisticação metodológica.

\footnotetext{
${ }^{5}$ Ver estudo anterior sobre o tema em dissertação de mestrado de Kim (1998).
} 
A progressiva expansão do conhecimento sobre metodologia e conceituação teórica é sintomática dos esforços efetuados para alcançar rigor e um reconhecimento de 'seriedade' em um campo de pesquisa ainda jovem. $O$ surgimento de desenvolvimento e impactos como domínio reflete uma preocupação substantiva muito particular por parte de vários pesquisadores.

[...] a presente pesquisa confirma resultados prévios no sentido de que este campo está, todavia, dominado pelo paradigma científico positivista, se bem que evidencia uma crescente contribuição do paradigma interpretativo e/ou da teoria crítica. (XIAO; SMITH, 2006, p. 147, tradução própria)

Ao final, ressaltam que o conteúdo de uma revista com a reputação do Annals of Tourism Research pode ajudar “os acadêmicos a ter um 'retrato completo' do alcance, limites e tendências nesse campo" (XIAO; SMITH, 2006, p. 147), apesar de ser um periódico com marcada perspectiva de Antropologia cultural e, portanto, orientado para as Ciências Sociais.

Esses mesmos autores, dois anos mais tarde, desenvolvem outra pesquisa sobre os impactos de um "corpus" de conhecimento - a Sociologia e a Antropologia do Turismo - na comunidade acadêmica, dentro e fora dos estudos turísticos. Com base em citações diretas ${ }^{6}$, co-citações ${ }^{7}$ e referências bibliográficas, utilizam como ferramenta o Google Scholar. (XIAO; SMITH, 2008)

De uma amostra inicial de 2.014 citações de artigos de revistas científicas, definem uma subamostra aleatória constituída de 201 artigos (16\% do total), na qual determinam a taxa de cocitações e os elos ou ligações bibliográficas associadas, estabelecendo as seguintes categorias de análise: Turismo, Sociologia e Antropologia; relação com o turismo ou não; e propriedades bibliográficas (autoria, ano, título, nome da revista, campos, disciplinas e idioma de publicação).

Dentre os resultados obtidos a respeito da estrutura dos impactos do conhecimento, os autores afirmam que, dos autores/títulos turísticos, 57\% das citações foram realizadas por autores e textos de turismo; as citações destes clássicos por autores fora do campo de turismo não são raras, somando $27 \%$. Verificam que esse conjunto de conhecimento representa uma distribuição entre 60 e $40 \%$ entre impactos de citações sobre o turismo frente a autores e títulos turísticos (XIAO; SMITH, 2008).

\footnotetext{
${ }^{6}$ Citação direta é o número de vezes que um título é citado em um documento.

${ }^{7}$ Co-citação é a freqüência com que 2 ou mais títulos são utilizados em pares ou trios em um documento.
} 
Ainda pontuam uma série de críticas sobre as pesquisas na área, como a falta de profundidade e a contínua citação de citação, e justificam a não utilização de bancos de dados tradicionais por apresentarem limitada inclusão de títulos turísticos. Destacam que a ferramenta utilizada, o Google Scholar, apresenta um grande número de fontes editoriais, e a opção de busca "citado por" relaciona documentos citados por uma fonte específica, sendo assim útil para estudos de impactos de citações.

A maioria das pesquisas analisadas neste item reforça o papel e a importância dos periódicos científicos no fluxo de comunicação científica, quer em relação a "rankings" desses veículos que avaliam a sua qualidade, quer em relação ao seu conteúdo como expressão do conhecimento científico. A última pesquisa citada avança na análise complexa de citações e nos impactos de um "corpus" de conhecimento específico, o da Sociologia e Antropologia do Turismo, justamente duas das áreas tradicionais de pesquisas de doutorado sobre temas turísticos.

\section{Pesquisas sobre a Produção Científica em Turismo: estudos referenciais no exterior, estudos referenciais no Brasil}

Os estudos sobre a produção científica em Turismo no país começaram a ser realizados na década de 1990, com o desenvolvimento de duas pesquisas acadêmicas. A primeira, uma tese de doutorado, enfocou a pesquisa científica em turismo, tratando inicialmente da sua evolução, natureza e dificuldades como fundamento para a configuração e sistematização documental de 55 dissertações e teses defendidas em instituições brasileiras, no período de 1975 a 1992 (REJOWSKI, 1993).

A segunda, uma tese de livre-docência (REJOWSKI, 1997), retomou o tema do doutorado com o aprofundamento das análises disciplinar, temática e metodológica dessa produção, a partir de um conjunto de 102 dissertações e teses sobre Turismo defendidas no período de 1973 a 1995. Paralelamente discorre sobre as opiniões de pesquisadores acadêmicos e empresários/profissionais turísticos sobre a pesquisa acadêmica na área, e conclui com propostas para a realização de pesquisas futuras e valorização desta e dos pesquisadores turísticos. Particularmente em relação à produção científica investigada, tem-se que: 
As teses concentram-se com maioria significativa em São Paulo [...]. [...] a maior produção quantitativa é de responsabilidade de instituições públicas, afirmando o pouco engajamento das instituições privadas na pesquisa.

[...] as três principais áreas produtoras de pesquisas turísticas continuam a ser a Comunicação, Administração e a Geografia [...], sendo a primeira delas a mais promissora [,,,].

Em relação à temática das teses, há concentração de pesquisas em oferta, desenvolvimento, marketing e planejamento turístico, além de turismo e espaço.

As pesquisas exploratórias aparecem em número maior [...]. Porém é significativo o aumento do número de pesquisas descritivas e explicativas, o que revela um nível de profundidade maior no estudo do Turismo [...]. (REJOWSKI, 1997, p. 132-133)

Interessante observar que o estudo da produção científica em turismo, um tema a princípio pouco atraente ou "inóspito" para os acadêmicos, teve continuidade em monografias de graduação, dissertações de mestrado, teses de doutorado, trabalhos apresentados em eventos e artigos de periódicos científicos, como descrito a seguir.

Gomes (2001) desenvolveu uma monografia de final de curso de graduação, intitulada Pesquisa acadêmica em turismo no Brasil, que apresenta a caracterização e análise disciplinar e temática das teses e dissertações em turismo defendidas no Brasil até dezembro de 2000. Aplica metodologia desenvolvida por Rejowski (1993 e 1997) e atualiza a base de dados desenvolvida por essa autora.

Sakata (2002), em sua dissertação de mestrado, aborda as tendências metodológicas da pesquisa acadêmica em turismo, analisando comparativamente as metodologias utilizadas nas pesquisas de mestrado produzidas na Universidade de São Paulo, na Universidade do Vale do Itajaí e no Centro Universitário Ibero-Americano. Dentre os resultados desse estudo, destacam-se os seguintes:

[...] quanto ao paradigma de pesquisa, tem-se em primeiro lugar de utilização o Paradigma Exploratório, seguido do Explicativo, Descritivo e Histórico. Quanto à Estratégia de Pesquisa, a mais utilizada é a pesquisa de Campo, seguida do Estudo de Caso, Estratégia Bibliográfica e Histórica. [...]

Nas Teses de Doutorado, [...] quanto ao Paradigma da Pesquisa, o que mais se destacou foi o Explicativo, seguido do Teórico, Exploratório-Descritivo e Exploratório. [...] Quanto à Estratégia de Pesquisa, duas que não figuram na lista dos quatro mais utilizados das Dissertações, aparecem aqui em destaque [...], a Fenomenologia [...] e a Etnografia [...]. (SAKATA, 2002, p. 61). 
Gomes (2004) retoma seus estudos sobre produção científica realizando uma dissertação de mestrado intitulada Pesquisa científica em lazer no Brasil - bases documentais e teóricas. Adaptando a metodologia de Rejowski (1997), discorre sobre as dissertações e teses sobre lazer produzidas no Brasil. Além de caracterizar e analisar disciplinarmente essa produção, identifica categorias temáticas, dentre as quais a de lazer turístico com 11 documentos (3\% do total). Nessa categoria, os temas abordados foram viagem de lazer, turismo social, ecoturismo e turismo receptivo com enfoque no lazer. Com base nas bibliografias específicas em turismo de cada documento, ainda discute as fontes básicas e o posicionamento teórico dessa produção acadêmica, concluindo o seguinte:

$\mathrm{Na}$ análise das referências bibliográficas é revelado o predomínio de autores como Joffre Dumazedier, Geraldo Castelli, Michael Mafessoli, Sarah Bacal, John Urry, Jost Krippendorf e Erik Cohen. [...]

Quanto aos documentos consultados pelos autores das teses, $44 \%$ referem-se a livros, $42 \%$ a artigos e $14 \%$ aos demais. Desses, $57 \%$ são produzidos por autores estrangeiros e $43 \%$ nacionais. [...]. Em relação ao posicionamento teórico e conceitual dos autores constata-se que, das 9 teses analisadas 5 foram agrupadas na categoria "sem posicionamento". (GOMES, 2004, p.13)

Em seguida, surgem dois estudos que abordam outro objeto de pesquisa, os artigos científicos publicados na revista Turismo em Análise ${ }^{8}$. O primeiro trata da produção do conhecimento na área do turismo (EIDT, 2004), buscando demonstrar quais os temas, objetos e metodologias presentes nos artigos publicados entre os anos 1995 e 2002. Para o autor,

[...] a Revista expressa uma diversidade de temas e uma relação do Turismo com outras áreas do conhecimento, tais como: Geografia, Administração, Comunicação, História, entre outras.

Quanto à abordagem metodológica, a pesquisa qualitativa é a abordagem mais utilizada pelos autores dos artigos analisados. Entre as pesquisas qualitativas, encontramos com maior freqüência os seguintes tipos de pesquisa: o estudo de caso, seguido da pesquisa documental e da análise comparativa. (EIDT, 2004, p. $43)$.

\footnotetext{
${ }^{8}$ Essa revista é editada pelo Curso de Turismo da Escola de Comunicações e Artes da Universidade de São Paulo desde 1990, sendo a primeira revista científica na área no Brasil.
} 
O segundo trabalho aplica a Cienciometria ${ }^{9}$ na análise dos artigos publicados nessa revista de 1990 a 2002, identificando as especificidades dos autores - procedência geográfica, áreas de formação, titulação, freqüência de publicação e temáticas investigadas (BERTUZZO, 2004b). A autora observa também "as fases de desenvolvimento do turismo no Brasil sob a luz da teoria das 'plataformas' do estudo do turismo de Jafar Jafari (1992), mostrando como as publicações deste periódico científico refletiram a realidade” do Turismo no Brasil:

A identificação das temáticas mais pesquisadas [...] sofre uma forte influência com a teoria criada por Jafari. As temáticas mais evidenciadas [...] (1990 a 1994) são: Planejamento Turístico, Destinações Turísticas, Economia do Turismo, InfraEstrutura Turística e Administração Turística [...] voltadas ao início do desenvolvimento da atividade turística, apontando [...] para a chamada plataforma de defesa. (BERTUZZO, 2004a, p. 80).

Em seguida Leal (2006) publica na revista Estudios y Perspectivas en Turismo ${ }^{10}$ resultados de um estudo exploratório na época em andamento no qual discute a maturidade da pesquisa científica em Turismo no Brasil e no mundo, a partir de três indicadores: publicações especializadas, pesquisadores reconhecidos e eventos acadêmicos. Mediante um painel de experts turísticos, levanta as opiniões destes sobre os mais reconhecidos pesquisadores, as publicações brasileiras mais relevantes e os mais importantes eventos científicos da área. Os resultados referentes a esses dois últimos itens indicaram que:

O número de publicações especializadas no Brasil ainda é pequeno, comparado com os países de maior tradição na oferta da educação superior na área. Durante a última década, devido a um aumento explosivo do número de cursos de graduação, a quantidade de livros didáticos cresceu significativamente. [...]

As revistas científicas de alcance nacional, por sua parte, não acompanharam o mesmo nível de crescimento dos livros, existindo na atualidade poucas revistas especializadas de qualidade reconhecida no país [...]: Turismo em Análise [...], Turismo: Visão e Ação, [...].

Os eventos mais citados pelos entrevistados foram: Seminário de Pesquisa em Turismo do Mercosul, [...] Encontro Nacional de Base Local, [...] e Congresso Brasileiro de Turismo. (LEAL, 2006, p. 85-89)

\footnotetext{
9 A Cienciometria, parte da Sociologia da Ciência, trata dos aspectos quantitativos da ciência, sendo utilizada para a definição de políticas científicas, como as referentes à publicação. Mediante técnicas métricas, avalia a ciência e analisa as políticas científicas de países. (ARAÚJO RUIZ; ARENCIBIA JORGE, 2002)

${ }^{10}$ Essa revista é publicada pelo CIET - Centro de Investigaciones y Estúdios Turísticos, de Buenos Aires (Argentina), sendo considerada uma das principais revistas científicas latino-americanas na área.
} 
Com isso, o estudioso conclui que apesar do Brasil situar-se "em uma etapa avançada de desenvolvimento da área junto a sua comunidade científica", encontra-se defasado frente " $a$ maior tradição da oferta de educação superior em turismo", pois para os experts brasileiros há poucos pesquisadores, periódicos e eventos científicos de grande relevância. (LEAL, 2006, p. 89)

Ainda em 2006, tem-se a publicação de um estudo no âmbito da Geografia do Turismo, cujos autores investigam como esse tema foi abordado em dois eventos da Associação dos Geógrafos Brasileiros (AGB) em 2002 e 2004. Galvão Filho e Huertas Calvente (2006) selecionam 135 artigos, classificando-os em sub-eixos temáticos, conforme o enfoque dado, e em áreas, de acordo com a natureza do espaço estudado; e, em cada sub-eixo, destacam os estudos que utilizaram a técnica de geoprocessamento.

Observam que a maioria dos artigos concentram-se nos sub-eixos impactos socioambientais do turismo (46) e turismo: planejamento e políticas públicas (28), alguns com uso de geoprocessamento (4 e 5 respectivamente). Os demais artigos distribuem-se nos seguintes sub-eixos temáticos, nos quais não houve o uso de geoprocessamento: aspectos culturais, religiosos e imaginários do turismo (22); turismo, geografia e ensino, (16); estudos das potencialidades turísticas (15); e tipologia dos fluxos turísticos (8). No tocante às áreas, identificaram áreas litorâneas (29), áreas rurais (12), áreas naturais (22), áreas urbanas nãolitorâneas (38), regiões brasileiras (13), sendo que alguns não citaram lugares específicos (20). Ao final, os autores destacam que a análise dos trabalhos nos sub-eixos temáticos proporcionou "leituras diversificadas de uma atividade complexa e transversal", com importante papel para o avanço da pesquisa: "conhecer o turismo realizado em diferentes localidades do país, estudado por diversas instituições, em diferentes níveis de pesquisa", certamente contribuirá "para reflexões cientificas se os pesquisadores estiverem dispostos a escutarem ou lerem o que o outro tem a dizer ou escrever". (GALVÃO FILHO; HUERTAS CALVENTE, 2006, p. 238-239)

Em 2007, tem-se um conjunto de trabalhos apresentados em eventos científicos em Turismo, o que demonstra um renovado interesse dos pesquisadores brasileiros sobre estudos da produção científica na área. 
Tratando de indicadores bibliométricos, tem-se o trabalho de Alberton e Lopes (2007) sobre a evolução da pesquisa em Turismo no Brasil no período de 1990 a 2005. A partir da distribuição de freqüências e medidas de estatística descritiva analisam 373 artigos de duas tradicionais revistas científicas no Brasil - Turismo em Análise e Turismo: Visão e Ação, mediante as seguintes variáveis: temas mais enfatizados, número de autores por artigo e filiação dos autores, metodologia, referências (diversidade e atualidade)

Como resultados apontam-se: média inferior a dois autores por artigo; predominância de estudos de caso e pesquisas documentais; média inferior a 20 referências por artigo, com maior incidência de nacionais e provenientes de livros, com cerca de 50\% defasadas em mais de cinco anos. (ALBERTON; LOPES, 2007, p. 1)

Nessa mesma linha, Souza e Pimentel Filho (2007) abordam os trabalhos sobre Turismo e Hotelaria publicados nos Anais do ENANPAD - Encontro Nacional da Associação Nacional de Pesquisa e Pós-Graduação em Administração, com base em estudo bibliométrico de caráter exploratório-descritivo. Identificam 67 artigos publicados nos anais desse evento no período de 1997 a 2006, os quais são estudados com base nas seguintes variáveis: ano de publicação do artigo, área temática, nome do autor e respectiva instituição, título do trabalho, objetivo, metodologia, principais resultados e conclusões.

De um total de 114 diferentes autores, alguns em co-autoria, somente 18 deles publicaram mais de um artigo. As principais instituições de filiação dos autores foram a Universidade Federal do Rio Grande do Norte e a Fundação Getúlio Vargas do Rio de Janeiro. Os trabalhos, distribuídos em diversas áreas temáticas, referem-se principalmente a: gestão pública e social no setor turístico, marketing de empresas e destinações, estratégia empresarial e setorial, e gestão de pessoas em organizações turísticas. A visão do Turismo nesses conteúdos é explicitada pelos autores, o que justifica a importância de estudos dessa natureza para a compreensão do conhecimento produzido na interface entre a Administração e o Turismo.

Embora estes trabalhos não sejam a única forma de se estudar o turismo, o conhecimento dos mesmos por pesquisadores da área podem auxiliar a compreensão de uma atividade tão complexa. Além disso, servem também para saber em quais IES se encontram os núcleos de pesquisa em turismo a fim de estabelecer redes de contatos para troca de informações e realização de trabalhos 
conjuntos, multidisciplinares e inter-institucionais. (SOUZA; PIMENTEL FILHO, 2006, p. 11-12)

Ainda com foco em trabalhos apresentados em eventos científicos, Hocayen-da-Silva e Gândara (2007) investigam a produção científica em Turismo, a partir dos trabalhos sobre marketing, qualidade e sustentabilidade publicados nos anais do ENTBL - Encontro Nacional de Turismo de Base Local, entre 2004 e 2005. Investigam 95 artigos publicados nos anais desse evento, relacionados ao marketing, qualidade e sustentabilidade, por meio das seguintes categorias de análise: número de autores por artigo, idioma do artigo, nacionalidade dos autores, instituição de origem dos autores, estado de origem dos autores, tipo de pesquisa, método de pesquisa e estratégia de pesquisa.

Verificam que a maioria dos artigos tratava do tema sustentabilidade (75\%), eram escritos em português $(99 \%)$, configuravam-se como de caráter teórico-empírico (81\%), qualitativos (78\%) e centravam-se em estudos de caso (78\%). A média de autores por artigo era a de 2, o que sugere pequena quantidade de publicações oriundas de grupos de pesquisa. Segundo os autores, o "trabalho contribui [...] para a apresentação dos caminhos que estão sendo percorridos pelos pesquisadores, bem como as tendências que poderão ser adotadas em futuras pesquisas da área" (HOCAYEN-DA-SILVA; GÂNDARA, 2007, p. 14).

Com foco no mercado editorial de livros, Panosso Netto (2007) trata da produção bibliográfica de turismo no Brasil, no período de 1990 a 2007, centrada em livros, mediante consulta a homepages de 27 editoras. Objetivando estabelecer um quadro geral dessa produção científica para a compreensão do conhecimento em turismo, pesquisa o tema a partir das seguintes variáveis: livros publicados por editoras, edições dos livros publicados e temas abordados nos mesmos.

Esse autor investiga 460 títulos, com uma média de 17 títulos por editora, em cujas temáticas destacam-se a de turismo em geral, planejamento e hotelaria. Conclui que a partir de 2002 a edição de livros de turismo no país entrou em declínio, justificada por um conjunto de fatores "que vão desde a diminuição da oferta de cursos superiores de turismo até o pouco interesse pela leitura por parte dos acadêmicos [...]" [PANOSSO NETTO, 2007, p. 1). 
Há outras pesquisas a serem citadas que procuram acompanhar a produção acadêmica de dissertações defendidas em programas de mestrado em Turismo e em Hospitalidade, aplicando e/ou adaptando metodologia de Rejowski (1997). Com foco nas dissertações de mestrado da Universidade de Caxias do Sul, tem-se os trabalhos de Quevedo et al. (2005) sobre as pesquisas produzidas no período de 2002 a 2004, de Pinto e Babinski (2006) sobre esse período e o subseqüente de 2004 a 2005, e de Figueiredo, Bacon e Rejowski (2007) referente ao período de 2002 a 2006. Neste último trabalho, as autoras analisam 57 dissertações, cujos dados foram registrados em uma ficha técnica com as seguintes variáveis: tema e sub-tema, local-foco e objeto de estudo. Dentre os resultados alcançados, verificam que:

O tema de maior destaque foi gestão do turismo e o principal local-foco de estudo foi a cidade de Caxias do Sul (RS), refletindo a origem da maioria dos mestres. Como objeto de estudo destacado em primeiro lugar aparece hotel, seguido de município e turista. Houve um aprimoramento e atualização do estudo dessa produção acadêmica [em relação à pesquisa desenvolvida por Quevedo et al.], cujos resultados se constituem em ferramenta estratégica para gestão deste Programa. (BACON; FIGUEIREDO; REJOWSKI, 2007, p. 1)

Tratando da produção acadêmica do Mestrado em Hospitalidade da Universidade Anhembi Morumbi, duas pesquisadoras também vêm desenvolvendo, desde 2006, pesquisas contínuas sobre as dissertações de mestrado produzidas nesse programa (BASTOS, 2005; BASTOS; FEDRIZZI, 2006; BASTOS; FEDRIZZI, 2007; BASTOS, 2008; FEDRIZZI, 2008).

Na última pesquisa publicada em 2008 na Revista Hospitalidade, Bastos (2008) sistematiza e configura a produção científica de um conjunto 132 dissertações defendidas naquele programa no período de 2002 a 2008, a partir de: abordagem de conteúdo do currículo Lattes dos autores (área de formação e instituição da graduação e pós-graduação); e dados referenciais das dissertações (título, resumo, ano de conclusão, nome do orientador, nome do autor e até 5 palavras-chave). A autora classifica as pesquisas mediante a ampliação dos eixos temáticos que constavam na proposta original do programa submetido à CAPES em $2001^{11}$

\footnotetext{
11 Os eixos temáticas da proposta original eram os seguintes:hospitalidade, turismo, restauração, meios de hospedagem e entretenimento.
} 
[...] a partir da freqüência das palavras-chaves (hospitalidade, ensino, religião, turismo, meios de hospedagem, hotelaria hospitalar), bem como a revisão das categorias entretenimento (desmembrado em eventos e lazer) e restauração (restaurante e gastronomia). [...]

Visando conhecer a derivação dos estudos do eixo temático Turismo, foram considerados os termos mais freqüentes, com pelo menos três repetições. Nesse sentido, [revelou-se] a preocupação com o desenvolvimento das localidades (3), o planejamento (4) e a gestão (5) dos destinos, bem como aqueles que tratam da gestão pública do Turismo (4) ou do trade, exemplificado, nesse caso, pelas agências de turismo (3). (BASTOS, 2008, p. 120 e 130)

Paralelamente, uma dessas dissertações desse programa, de autoria de Fedrizzi (2008), tratou especificamente do conhecimento nele gerado com base em referencial da Ciência da Informação. Os títulos, os resumos e as palavras-chave das dissertações defendidas de 2004 a 2007 foram investigados por meio de abordagens temporais, territoriais e temáticas, acrescidas pela coleta de dados dos currículos Lattes ${ }^{12}$ dos respectivos autores. Dentre os resultados citam-se os relacionados às suas facetas temáticas:

[...] implementou-se a indexação das 108 dissertações dentro de uma única categoria Hospitalidade e criaram-se dez facetas através do método analítico, indexando-se cada dissertação em uma única faceta (classe) interpretativa (auto excludente). As facetas configuram um sistema, composto por Hospitalidade turística (18), Hospitalidade comportamental (15), Hospitalidade espacial (14), Hospitalidade e eventos (9), Hospitalidade e meios de hospedagem (13), Hospitalidade e ensino (10), Hospitalidade e restauração (7), Hospitalidade e gestão (12), Hospitalidade religiosa (4) e Hospitalidade organizacional (6). (FEDRIZZI, 2008, s. p.)

Percebe-se assim que a faceta hospitalidade turística se destacou na geração de conhecimento em Hospitalidade no contexto daquele programa, reforçando a sua estreita relação entre o Turismo e a Hospitalidade, campos recentes de estudo e investigação que se integram estabelecendo múltiplas relações.

Ainda em 2008, no V Seminário da Associação Nacional de Pesquisa e Pós-Graduação em Turismo, formou-se um grupo de trabalho intitulado Produção Científica em Turismo e

\footnotetext{
12 A plataforma Lattes é uma base de dados de currículos e instituições das áreas de Ciência e Tecnologia criada
} pelo CNPq - Conselho Nacional de Desenvolvimento Científico e Tecnológico, disponível “on line”. 
Hospitalidade, no qual foram apresentados 14 trabalhos científicos. Desses, merecem menção 4 deles.

Spolon e Motoda (2008) tratam da produção científica em Turismo e Hospitalidade no Brasil oriunda de seis universidades com 6 programas de mestrado e 2 de doutorado. A análise de 606 dissertações e teses, distribuídas em 16 áreas de estudo, indicou como principais assuntos abordados os seguintes: cultura e patrimônio (edificado, natural, imaterial), meio ambiente e sustentabilidade (áreas protegidas, impactos do turismo em áreas naturais), planejamento (planos de desenvolvimento do turismo) e marketing turístico (oferta e fluxos de demanda, promoção turística). Para esses estudiosos, embora existam temas prioritariamente de interesse dos pesquisadores brasileiros, as pesquisas estavam relativamente bem distribuídas, considerando-se as propostas pedagógicas dos programas existentes.

Referente a programas de pós-graduação "stricto sensu" em Turismo, Biz et al. (2008) investigam a produção científica dos 56 docentes doutores de 4 desses programas. Mediante a aplicação de questionário oriundo da planilha de avaliação da CAPES e da análise de currículos Lattes no período de 2004 a 2007, abordam a produtividade intelectual dos doutores (artigos de periódicos e de eventos científicos), os projetos financiados (bolsistas de órgãos de apoio à pesquisa federal e estadual) e as pesquisas em rede (internacional, nacional ou local).

Observam uma freqüência média de publicação de artigos em anais de eventos científicos e em periódicos científicos, a maioria não classificados na lista Qualis da Capes. Também notam a ausência de artigos de periódicos internacionais classificados na lista Qualis ${ }^{13}$, como o Annals of Tourism Research, Tourism Management, Journal of Travel \& Tourism Marketing, e The International Journal of Tourism Research. Citam também que havia poucos discentes com bolsas de pesquisa oferecidas por órgãos públicos federais e estaduais ou organizações privadas, e identificam somente duas pesquisas em rede, uma internacional e uma local, registradas em currículos Lattes de docentes da Universidade do Vale do Itajaí.

\footnotetext{
${ }^{13}$ A CAPES - Coordenação de Aperfeiçoamento de Pessoal de Nível Superior, órgão do Ministério da Educação no Brasil e responsável pela avaliação dos programas de pós-graduação "stricto sensu", ou seja, mestrados e doutorados. Esse órgão, no âmbito dessa avaliação, instituiu um conjunto de procedimentos para a estratificação da qualidade da produção científica de docentes e discentes desses programas, que resultou em uma lista, denominada Qualis.
} 
Em outro trabalho apresentado naquele evento, Moraes (2008) aborda a produção científica sobre o tema eventos no estado de São Paulo, analisando um conjunto de 27 pesquisas, sendo 5 teses de doutorado e 22 dissertações de mestrado defendidas em programas de pósgraduação "stricto sensu" da Universidade de São Paulo e da Universidade Anhembi Morumbi. Fundamentada em metodologias propostas por Rejowski (1993 e 1997) e Gomes (2004), a pesquisadora apresenta resultados preliminares de pesquisa sobre a caracterização geral, o conteúdo disciplinar e temático, e a bibliografia relacionada aos documentos selecionados. Em relação a este último aspecto, discute as bases documentais que fundamentaram essas pesquisas (autores, obras, temáticas, referências): 481 referências bibliográficas, sendo 421 em papel e 60 eletrônicas. Observa resultados tais como:

Quanto aos documentos consultados pelos autores das teses, $83 \%$ referem-se a livros e artigos publicados em papel, $11 \%$ a artigos e pesquisas em publicação eletrônica e $6 \%$ a outros tipos de documentos consultados. Comprovando que há pouca publicação científica sobre o objeto estudado, apenas $9 \%$ das referências consultadas eram sobre eventos. (MORAES, 2008, p. 9)

[Em relação à produção da Universidade Anhembi Morumbi,] a hospitalidade é o posicionamento teórico principal [dos autores] e, dependendo da temática ou do orientador, altera-se o posicionamento teórico sobre eventos baseados na área das Ciências da Comunicação ou das Ciências Sociais.

Portanto, percebe-se que não existe um posicionamento teórico e conceitual, talvez, em função da pouca produção científica e por ser Eventos um campo do conhecimento e não uma disciplina ou ciência. (MORAES, 2008, p. 12).

Por fim cita-se a pesquisa de Oliveira e Rejowski (2008), apresentada no XXXI Congresso Brasileiro de Ciências da Comunicação, sobre a categoria temática desenvolvimento do turismo presente nas dissertações e teses em Turismo no Brasil. Após considerações sobre estudos da produção científica na área e os significados do termo desenvolvimento na literatura científica, os autores estudam 31 teses de doutorado distribuídas no período de 1985 a 2005, a maioria (28 pesquisas) oriunda de instituições de ensino superior públicas.

Constatam que as teses que abordavam o tema desenvolvimento do turismo, trataram principalmente do desenvolvimento sustentável (10), seguidas das que abordaram o desenvolvimento urbano (6), desenvolvimento regional (5), desenvolvimento territorial (4), e desenvolvimento econômico, desenvolvimento do espaço e desenvolvimento social (1 em 
cada); algumas não esclareceram a abordagem adotada acerca do desenvolvimento 92). Com relação aos temas secundários e terciários (subtemas) ressaltam que:

Os temas secundários [..] indicam vários interesses temáticos: Sustentabilidade, expressa pelos termos Turismo Sustentável, Ecoturismo e Turismo Ecológico; Espaço Turístico, Planejamento e (Re)Ordenamento e Território/Territorialidade Turística; Urbanização Turística; Turismo Sustentável, Impactos etc.; interessante é o Valor Econômico abordado quanto aos recursos ambientais (paisagem)

Passando para o tema terciário, nota-se uma predominância pela Política, assim expressa: Politica Integrada, Política Pública, Política Ambiental, Políticas Públicas, Políticas, Práticas Políticas; em seguida aparece o grupo de Cluster, Cluster Ecoturísticos, Microcluster e Arranjo Produtivo Local. (OLIVEIRA; REJOWSKI, 2008, p. 11-12).

Considera-se essa pesquisa como uma iniciativa pioneira no Brasil no âmbito de estudos sobre a validação de uma categoria temática das pesquisas turísticas. Porém concorda-se com os próprios autores de que para atestá-la, há necessidade de outros estudos mais aprofundados que analisem maior volume de produção.

Encerrando este item, apresenta-se uma síntese das características gerais dos estudos referenciados. De todos os autores, apenas um se encontrava vinculado à instituição de ensino superior do exterior (Sergio Leal), sendo que os demais se vinculavam principalmente a instituições do estado de São Paulo, além de outras instituições de diversos estados - Paraná, Santa Catarina e Rio Grande do Sul. Em um total de 24 pesquisas, 2 foram produzidas na década de 1990 (1993 e 1997) e as demais na década de 2000, sendo o biênio 2007-2008 responsável por mais da metade delas (13 pesquisas).

Esse resultado indica o interesse recente de pesquisadores pelo tema no Brasil, principalmente os da área de Turismo (11 pesquisas) e da Hospitalidade (6 pesquisas). Aparecem ainda pesquisadores das áreas de Comunicação, Ciência da Informação e Geografia, além de pesquisadores oriundos de áreas híbridas - Turismo e Lazer, e Administração e Turismo.

Quanto aos objetos de pesquisa tratados, têm-se primariamente as dissertações de mestrado e/ou teses de doutorado, seguidas pelos artigos publicados em anais de eventos científicos e em periódicos científicos. Há apenas uma pesquisa referente a livros, e outra que trata de vários objetos da produção científica não restrita a publicações. 


\section{Considerações Finais}

A amostra de trabalhos sobre o tema publicados no exterior ressalta o interesse de pesquisadores pela compreensão da evolução do conhecimento turístico, em geral com base em pesquisas quantitativas e clara preferência pelos periódicos científicos enquanto objeto de estudo. Dentre esses, aparece destacadamente o Annals of Tourism Research, reconhecido como o mais importante veículo de comunicação científica da área.

Causou surpresa descobrir o interesse de pesquisadores portugueses e espanhóis sobre o tema, e ao mesmo tempo a necessidade de um levantamento mais exaustivo da literatura, principalmente no contexto sul-americano, uma vez que não foram identificados estudos oriundos dessa região publicados até 2008 .

Em uma trajetória diacrônica, apresentou-se um conjunto de estudos sobre a produção científica em Turismo no Brasil, que configura um verdadeiro fluxo de comunicação científica das pesquisas concluídas para novas pesquisas. Essa produção estimulou a criação de um grupo de trabalho específico no Seminário da ANPTUR, o que demonstra o interesse dos pesquisadores brasileiros em investigar a produção científica para a melhor compreensão e organização do conhecimento científico em Turismo. Verificou-se que a maioria dessas pesquisas aborda dissertações e teses acadêmicas ou periódicos científicos, em especial duas revistas, a Turismo em Análise e a Turismo-Visão \& Ação, por serem veículos qualificados que reúnem volumes substantivos de documentos passíveis de serem analisados. Ao mesmo tempo os estudos sobre outros veículos como livros, trabalhos em anais de eventos, bolsas de estudo e pesquisas em redes de pesquisadores, pouco presentes na literatura estrangeira, mostram promissores caminhos a serem trilhados por pesquisas futuras.

Especificamente quanto às pesquisas sobre as dissertações produzidas pelo Mestrado em Hospitalidade da Universidade Anhembi Morumbi, observa-se que a sua continuidade e revisão constantes, possibilitam o aprofundamento das análises. Oferece, assim, uma "radiografia" sobre o conhecimento oriundo desse programa, que poderá subsidiar futuras reorientações de áreas de concentração, linhas de pesquisa ou até a formatação de um doutorado na área.

Embora cada uma das pesquisas tenha as suas particularidades, considera-se que houve avanços nos estudos sobre a produção científica em Turismo, em termos teóricos e 
principalmente metodológicos no exterior, e em termos de diversificação de objetos de estudo no Brasil. Mas em ambos os casos notou-se que são raros os estudos a integrar diferentes áreas de conhecimento. Daí a necessidade de se contar com equipes e grupos de pesquisa que promovam o diálogo interdisciplinar entre o Turismo e áreas como a Ciência da Informação, Comunicação, Geografia e/ou Administração. Finalmente sugere-se a realização de pesquisas inovadoras de maior envergadura, saindo da periferia e "mergulhando" no âmago da produção científica em Turismo no Brasil.

\section{Referências}

ALBERTON, Anete; LOPES, Vanessa Junqueira. 2007. Um estudo sobre a pesquisa em turismo no Brasil: análise de dois periódicos Qualis/Capes. In: SEMINÁRIO DA ASSOCIAÇÃO NACIONAL DE PESQUISA E PÓS-GRADUAÇÃO EM TURISMO, IV. Anais do IV Seminário da Associação Nacional de Pesquisa e Pós-Graduação em Turismo. São Paulo: Editora Aleph, CD-ROM.

ARAÚJO RUIZ, Juan A.; ARENCIBIA JORGE, Ricardo. 2002. Informetría, bibliometría y ciienciometría: aspectos teórico-prácticos. Acimed, Habana, v. 10, n. 4, jul.-ago. Disponível em: $<$ http://scielo.sld.cu/scielo.php?pid=S102494352002000400004\&script=sci_arttext $>$. Acesso em 13 fev. 2007.

BASTOS, Sênia. 2008. A produção científica do Mestrado em Hospitalidade (2002-2008). Revista Hospitalidade. São Paulo, ano V, n. 2, p. 120-132, jul.-dez. 2008.

2005. Produção acadêmica do mestrado em Hospitalidade. Revista Hospitalidade, São Paulo, ano II, n. 1, p. 89-95, 2005.

; FEDRIZZI, Valéria L.F. 2007. Produção acadêmica do mestrado em Hospitalidade. Revista Hospitalidade, São Paulo, ano IV, n.1, p. 123-138, 2007.

; _ 2006. Produção acadêmica do Programa de Mestrado em Hospitalidade. Revista Hospitalidade, São Paulo, ano III, n. 1, p. 99-106, 2006.

BERTUZZO, Gleid Maria Pereira. 2004 a. Produção científica: um estudo cienciométrico do periódico Turismo em Análise. In: SEMINÁRIO DE PESQUISA EM TURISMO, II, 2004. Anais do II Seminário de Pesquisa em Turismo do Mercosul. UCS: Caxias do Sul, 2004a. CD-ROM.

. 2004 b. Produção científica: um estudo cienciométrico do periódico Turismo em Análise. Campinas, Dissertação (Mestrado em Ciência da Informação) - PUC Campinas.

BIZ, Alexandre Augusto et al. 2008. Análise da produção científica dos docentes doutores dos programas de pós-graduação stricto sensu em turismo e hotelaria. In: SEMINÁRIO DA ASSOCIAÇÃO NACIONAL DE PESQUISA E PÓS-GRADUAÇÃO EM TURISMO, V, 2008. Anais do V Seminário da Associação Nacional de Pesquisa e Pós-Graduação em Turismo. São Paulo: Aleph, 2008, p. 1- 12.

BOTERILL, David. 2002. A survey of doctoral theses accep universities in the UK and Ireland related to tourism, 1990-1999. Tourist Studies, v. 2, n. 3, p. 283-311.

EIDT, Kleber Rodolfo Gauer. 2004. Turismo em Análise: a produção do conhecimento na área do turismo. Balneário Camboriú. Dissertação (Mestrado em Turismo e Hotelaria) - Universidade do Vale do Itajaí. 
FEDRIZZI, Valéria Luiza Ferreira. 2008. Conhecimento Gerado no Programa de Mestrado em Hospitalidade da Universidade Anhembi Morumbi. São Paulo, 2008. Dissertação (Mestrado em Hospitalidade) - Universidade Anhembi Morumbi.

FIGUEIREDO, Franciele B.; BACCON, Melissa; REJOWSKI, Mirian. 2007. Perfil e "performance" dos mestres em turismo da Universidade de Caxias do Sul - 2002 a 2006. In: SEMINÁRIO DA ASSOCIAÇÃO NACIONAL DE PESQUISA E PÓS-GRADUAÇÃO EM TURISMO, IV, 2007. Anais do IV Seminário da Associação Nacional de Pesquisa e Pós-Graduação em Turismo. São Paulo: Editora Aleph, 2007. CD-ROM.

GALEMBERK, F. 1990. Sem avaliação, sem progresso. Ciência e Cultura. v. 19, n. 9, p 627-628.

GALVÃO FILHO, Carlos Eduardo P.; HUERTAS CALVENTE, Maria Del Carmen M. 2006. A geografia brasileira e os estudos relacionados ao turismo: uma análise dos trabalhos de dois eventos nacionais (2002 e 2004). Geografia, Londrina, v. 15, n. 1, jan./jun. p. 221-242.

GOMES, C.M. 2001. Pesquisa acadêmica em turismo no Brasil - 1990/2001. São Paulo, 2001. Monografia (Trabalho de Conclusão de Curso em Turismo) - Escola de Comunicações e Artes, Universidade de São Paulo.

2004. Pesquisa Científica em Lazer no Brasil: bases Documentais e Teóricas. São Paulo, 2004. Dissertação (Mestrado em Ciências da Comunicação) - Escola de Comunicações e Artes, Universidade de São Paulo.

HALL, Michael. 1991. Tourism as a subject of a postgraduate dissertation in Australia. Annals of Tourism Research, Menomonie, v. 18, n. 3, p. 520-523.

HOCAYEN-DA-SILVA, Antônio; GÂNDARA, José Manoel G. 2007. Marketing, qualidade e sustentabilidade: análise da produção científica do Encontro Nacional de Turismo de Base Local ENTBL, nos anos de 2004 e 2005. In: SEMINÁRIO DA ASSOCIAÇÃO NACIONAL DE PESQUISA E PÓS-GRADUAÇÃO EM TURISMO, IV, 2007. Anais do IV Seminário da Associação Nacional de Pesquisa e Pós-Graduação em Turismo. São Paulo: Editora Aleph, CD-ROM.

JAFARI, Jafar; AASER, Dean. 1988. Tourism as the subject of doctoral dissertations. Annals of Tourism Research. Menomonie, University of Wisconsin-Stout, v.15, p.407-429.

JAMAL, Tazim; SMITH, Brian; WATSON, Elizabeth. 2006. Ranking, rating and scoring of tourism journals: interdisciplinary challenges and innovations. Tourism Management, London, Elsevier, n. 29, p. 66-78.

KIM, Seon-Ha. 1998. Content analysis: Annals of Tourism Research and Journal of Travel Research. University of Wisconsin-Stout (Master of Science in Hospitality and Tourism).

LEAL, Sergio Rodrigues. 2006. Madurez de la investigación científica en turismo en Brasil y en el mundo. Estudios y Perspectivas en Turismo, Buenos Aires: Ciet, v.15, n. 1, p. 81-95.

MCKERCHER, Bob; LAW, Rob; LAM, Terry. 2006. Rating tourism and hospitality journals. Tourism Management, London, Elsevier, n. 26, p. 1235-1252.

MORAES, Claudia Corrêa de Almeida. 2008. Panorama da pesquisa científica em eventos no estado de São Paulo - estudos introdutórios. In: SEMINÁRIO DA ASSOCIAÇÃO NACIONAL DE PESQUISA E PÓS-GRADUAÇÃO EM TURISMO, V, 2008. Anais do V Seminário da Associação Nacional de Pesquisa e Pós-Graduação em Turismo. São Paulo: Aleph, p. 1- 13.

OLIVEIRA, Jurandir Chaves de; REJOWSKI, Mirian. 2008. Teses em turismo no Brasil: categoria temática "desenvolvimento do turismo". In: CONGRESSO BRASILEIRO DE CIÊNCIAS DA COMUNICAÇÃO, XXXI, 2008, Natal. Anais do XXXI Congresso Brasileiro de Ciências da Comunicação - Mídia, ecologia e sociedade. São Paulo: Intercom, v. 1. p. 1-14. 
PANOSSO NETTO, Alexandre. 2007. Análise da produção bibliográfica de turismo do Brasil. In: SEMINÁRIO DA ASSOCIAÇÃO NACIONAL DE PESQUISA E PÓS-GRADUAÇÃO EM TURISMO, IV, 2007. Anais do IV Seminário da Associação Brasileira de Pesquisa e Pós-Graduação em Turismo. São Paulo: Aleph, CD-ROM.

PECHLANER, Harald et. al. 2004. A ranking of international tourism and hospitality journals. Journal of Travel Research, USA, Travel and Tourism Research Association, may, p. 328-332.

PINTO, Débora B.; BABINSKI, Luciana R. 2006. Produção acadêmica do mestrado em turismo da Universidade de Caxias do Sul: estudo comparativo das dissertações (2002 a 2004 - 2004 a 2005). CONFERÊNCIA DA AMFORHT PARA AMÉRICA LATINA, III, 2006. Anais da III Conferência de Amforht para América Latina. SENAC-SP: São Paulo.

QUEVEDO, Mariana F. et al. 2005. Produção acadêmica em Turismo - dissertações do mestrado em turismo da Universidade de Caxias do Sul (2002 a 2004). In: SEMINÁRIO DA ASSOCIAÇÃO NACIONAL DE PROGRAMAS DE PÓS-GRADUAÇÃO EM TURISMO, II, 2005, Balneário Camboriú. Anais do II Seminário da Associação Brasileira de Pesquisa e Pós-Graduação em Turismo. Balneário Camboriú: UNIVALI, v. 1. p. 1-16.

REJOWSKI, M. 1997. Realidade turística nas pesquisas científicas: visão de pesquisadores e profissionais. São Paulo, 2v. Tese (Livre Docência) - Escola de Comunicações e Artes, Universidade de São Paulo.

1993. Pesquisa acadêmica em turismo no Brasil (1975 a 1992): configuração e sistematização documental. São Paulo, 2v. Tese (Doutorado em Ciências da Comunicação) - Escola de Comunicações e Artes, Universidade de São Paulo.

SAKATA, M.C.G. 2002. Tendências metodológicas da pesquisa acadêmica em turismo. São Paulo, 104f. Dissertação (Mestrado em Ciências da Comunicação) - Escola de Comunicações e Artes, Universidade de São Paulo.

SOUZA, Maria José Barbosa de; PIMENTEL FILHO, Gilberto. 2007. Análise bibliométrica da produção científica em turismo publicada nos anais do ENAPAD. In: SEMINÁRIO DA ASSOCIAÇÃO NACIONAL DE PESQUISA E PÓS-GRADUAÇÃO EM TURISMO, IV, 2007. Anais do IV Seminário da Associação Nacional de Pesquisa e Pós-Graduação em Turismo. São Paulo: Editora Aleph, CD-ROM.

SPOLON, Ana Paula Garcia. MOTODA, Mauro. 2008. Novos caminhos da pesquisa acadêmica: a produção brasileira recente em turismo e hospitalidade. In: SEMINÁRIO DA ASSOCIAÇÃO NACIONAL DE PESQUISA E PÓS-GRADUAÇÃO EM TURISMO, V, 2008. Anais do V Seminário da Associação Nacional de Pesquisa e Pós-Graduação em Turismo. São Paulo: Aleph, p. 1- 14.

XIAO, Honggen; SMITH, Stephen L.J. 2008. El impacto del conocimento: una evaluación de la erudición en turismo. Annals of Tourism Research en Español, Universidad de les Illes Baleares, España, v.10, n. 1, p. 1-25.

2006. La génesis de la investigación turística: el análisis de una publicación de ciencias sociales. Annals of Tourism Research en Español, Universidad de les Illes Baleares, España, v.8, n.1, p. 131-151.

\section{Recebido em: 11/10/2009}

Aprovado: 06/04/2010 